\title{
CONGENITAL MALFORMATION OF THE INTESTINAL TUBE.
}

[Communicated for the Boston Medieal and surgical Journa].]

Mrs. J. S., aged 26, was delivered at full time, Wodnesday, July 28th, at 10 o'clock, A. M., of her first child (a male), weighing eight pounds. 'There was nothing unusual about the labor, only that it was protracted, and from inefficiency of action ergot was successfully used. The child was well formed, and there was at its birth every appearance of its doing well. It, however, soon commenced vomiting, which continued frequently for two days, and everything given was soon ejected from the stomacli. On the second and third days, at two different times, a very little, say a drachrn, of green and slimy matter was discharged from the bowels. The tube of a twomounce syringe readily passed into the rectum, but the injection returned. All means of relief failed, and the child began to falter the second day, and continued to fail, till it expired at $3 \frac{1}{2} o^{\prime}$ clock, Saturday, July 31st, being a little more than three days from birth.

Examination.-The body was examined five hours after death, the dissection being made by Dr. J. B. S. Jackson, of this city. The stomach, duodenum, jejunum, and to about the middle of the ileum, were of the usual size and appearance. About the middle of the ileum, the bowel abruptly contracted to less than the size of a common quill, and thus continued through the colon and rectum to its termination. The contracted parts were of a light color, and their convolutions had the appear. ance of masses of lumbrici coiled together. No fluid could be made to pass from the uncontracted into the contracted bowel below. The examination most satisfactorily accounted for the death of the child. The heart, lungs, liver, kidneys, \&c., were natural in their appearance.

Boston, August 2d, 1847.

Geo, HubBard,

THE BOSTON MEDICAL AND SURGICAL JOURNAL.

BOSTON, A U,G U T 11, 1847 .

Surgical and Mechanical Dentistry,-An increased attention to the subject of dentistry is indicated of late by the multiplication of treatises; and there is need enough of them. With all the science and nechanical skill of those who have raised and are continually elevating their profession, the country sivarms with a set of reckless men, who are doing an amount of mischief which all the properly taught dental operators in America can hardly repair. New and useful publications appear none too frequently, If they influence the people to encourage those only who are actually masters of their business, an important point will be gained. This is a country of bad teeth and bad dentists; but with the efforts now making by compotent writers, the dental colleges, and the co-operation of an enlightened public sentiment, the hope may be indulged of ultimately having the very best operators in the world, wherever the demand for the services of tho craft exists. 